\title{
Diketopyrrolopyrrole based small molecules with near infrared absorption for solution processed organic solar cells
}

Huijing Zhang, Nailiang Qiu, Wang Ni, Bin Kan, Miaomiao Li,Qian Zhang, Xiangjian Wan, * Yongsheng Chen*

${ }^{1}$ State Key Laboratory and Institute of Elemento-Organic Chemistry, Collaborative Innovation Center of Chemical Science and Engineering (Tianjin), School of Materials Science and Engineering, Nankai University, Tianjin 300071, China.

${ }^{2}$ Key Laboratory of Functional Polymer Materials and the Centre of Nanoscale Science and Technology, Institute of Polymer Chemistry, College of Chemistry, Nankai University, Tianjin, 300071, China

*Corresponding authors.Fax: +86-(22)-2349-9992. E-mail:xjwan@ nankai.edu.cn (X. Wan),yschen99@nankai.edu.cn (Y. Chen).

\begin{abstract}
Two small molecules DOR2TDPP andDCAO2TDPPwith a diketopyrrolopyrrole (DPP) unit as the central building block have been designed and synthesized for solution-processed bulk-heterojuntion (BHJ) solar cells. The two molecules in films exhibited broad absorption ranging from 300 to $900 \mathrm{~nm}$ with optical bandgaps of around $1.40 \mathrm{eV}$. The BHJ solar cell devices based on the DOR2TDPPand DCAO2TDPP as donors and $\mathrm{PC}_{71} \mathrm{BM}$ as acceptors gave a PCE of $2.05 \%$ and $1.09 \%$, respectively, under the illumination of AM.1.5G, $100 \mathrm{~mW} \mathrm{~cm}{ }^{-2}$. The influence of blend ratio of donor/acceptor and amount of additive on the performance of the solar cell were studied systematically.
\end{abstract}

Key words: small molecule, organic solar cell, diketopyrrolopyrrole, near infrared absorption

\section{Introduction}

Organic solar cells (OSCs) have attracted great attentions due to the potential advantages such as low cost, flexibility and etc. In contrast to the widely studied polymer based OSCs, small molecular organic solar cells (SM-OSCs) demonstrated many outstanding advantages, such as well-defined structure and definite molecular weight, easiness to purification, and thus little 
batch-to-batch variation. Recently, the power conversion efficiency (PCE) of $\sim 10 \%{ }^{[1-3]}$ has been achieved for SM-OSCs, indicating that the PCE of SM-OSCs could be indeed comparable with that of polymer solar cells ${ }^{[4-11]}$ and even higher PCEs could be expected for SM-OSCs through combination of delicate molecule design and device optimization. The PCE of OSC are determined by three parameters, open circuit voltage (Voc), short circuit current density (Jsc) and fill factor (FF). Generally, SM-OSCs have a high Voc and FF over $70 \%$ have also been achieved for many SM-OSCs. So, to improve the Jsc without sacrificing the Voc and FF is one of the effective strategies to get high PCE for OSCs. There are many methods to improve the Jsc, such as active layer morphology controlling by adding additives ${ }^{[12-14]}$, thermal annealing ${ }^{[15]}$,solvent vapor annealing $^{[16-17]}$, modification of buffer layer ${ }^{[18]}$,applying anti-reflection coating ${ }^{[19-20]}$, and so on. In fact, the direct and fundamental strategy to improve the Jsc is to design new donor molecules with broad light absorption range and high harvest efficiency.

The diketopyrrolopyrrole (DPP) unit, as a well known dye unit with many excellent properties such as strong light absorption, photochemical stability, good charge carrier mobility and etc., have been widely used not only in polymers based OSCs but also in SM-OPVs. In 2009, a DPP unit based molecule was reported with a PCE of $4.4 \%$, which was the highest PCE in the field of solution processed SM-OSCs at that time ${ }^{[21]}$. Nowadays, various DPP based small molecules have been designed $^{[22]}$. All of them have symmetric molecule structures, in which the DPP unit serves as the central core or end unit..Recently, our group have reported series of donor molecules with an acceptor-donor-acceptor (A-D-A) structure and PCEs around $10 \%$ have been achieved ${ }^{[1-3,23-25]}$. In order to extend the light absorption range, herein, we introduce the DPP unit as the central core, two electron withdrawing groups (octyl cyanoacetate and 3-ethylrhodanine) as end groups and design two small molecules DOR2TDPPand DCAO2TDPP. As expected, the two molecules exhibit broad 
and red shift solar absorption in contrast to our reported molecules. Initial PCEs of $2.07 \%$ and $1.10 \%$ were achieved for the molecules DOR2TDPP and DCAO2TDPP based devices with $\mathrm{PC}_{71} \mathrm{BM}$ as acceptors, respectively.

\section{Materials and methods}

\subsection{Materials}

All reactions and manipulations were carried out under argon atmosphere with the use of standard Schlenk techniques. Unless otherwise specified, all the starting materials were purchased from commercial suppliers which were used without any purification. The intermediate M2was synthesized according to the method we have reported ${ }^{[26]}$.

\subsection{Instruments and Measurements}

Nuclear magnetic resonance $\left({ }^{1} \mathrm{H}\right.$ NMR and ${ }^{13} \mathrm{C}$ NMR $)$ spectra were taken on a Bruker AV400 Spectrometer. MALDI-TOF spectra were performed on a Bruker Autoflex III instrument. The thermogravimetric analysis (TGA) was carried out on a NETZSCH STA409PC instrument under nitrogen gas flow with a $10{ }^{\circ} \mathrm{C} \mathrm{min}^{-1}$ heating rate. UV-Vis spectra were obtained with a JASCO V-570spectrophotometer. The organic molecule films on quartz used for absorption spectral measurement were prepared by spin-coating their chloroform solutions. X-Ray diffraction (XRD)experiments were performed on a Rigaku D/max-2500 X-ray diffractometer with $\mathrm{Cu}-\mathrm{K} \alpha$ radiation $(\mathrm{k}=1.5406 \AA)$ at a generator voltage of $40 \mathrm{kV}$ and a current of $100 \mathrm{~mA}$. Cyclic voltammetry (CV) experiments were performed with a LK98B II microcomputer-based electrochemical analyzer in $\mathrm{CH}_{2} \mathrm{Cl}_{2}$ solutions which were carried out at room temperature employing a glassy carbon electrode as the working electrode, a saturated calomel electrode (SCE) as the reference electrode, and a Pt wire as the counter electrode. Dichloromethane was distilled from calcium hydride under dry nitrogen immediately prior to use. Tetrabutylammonium 
phosphorus hexafluoride $\left(\mathrm{Bu}_{4} \mathrm{NPF}_{6}, 0.1 \mathrm{M}\right)$ in dichloromethane was used as the supporting electrolyte, and the scanning rate was $100 \mathrm{mV} \mathrm{s}^{-1}$.

2.3 Fabrication and characterization of SM-OSCs.

The photovoltaic devices were fabricated with a structure of glass/ITO/PEDOT:PSS/Donor:Acceptor/LiF/Al. The ITO coated glass substrates were cleaned by ultrasonic treatment indetergent, deionized water, acetone, and isopropyl alcohol under ultrasonication for $15 \mathrm{~min}$ each and dried by a nitrogen blow. PEDOT:PSS layer was spin-coated (3000 rpm, ca. $\sim 40 \mathrm{~nm}$ thick) onto the cleaned ITO surface. The substrates were then placed into an argon-filled glove box after being baked at $150{ }^{\circ} \mathrm{C}$ for $20 \mathrm{~min}$. Subsequently, the active layer was spin-coated from different blend ratios (weight-to-weight) of donor $\left(8 \mathrm{mg} \mathrm{mL}{ }^{-1}\right)$ and $\mathrm{PC}_{71} \mathrm{BM}$ in chloroform solution at $1700 \mathrm{rpm}$ for $20 \mathrm{~s}$ on the ITO/PEDOT:PSS substrate. The active layer thickness was measured using a Dektak150 profilometer. Finally, a $\sim 1 \mathrm{~nm} \mathrm{LiF}$ layer and a $\sim 80$ $\mathrm{nm} \mathrm{Al} \mathrm{layer} \mathrm{were} \mathrm{deposited} \mathrm{on} \mathrm{the} \mathrm{active} \mathrm{layer} \mathrm{under} \mathrm{high} \mathrm{vacuum}\left(<1.5 \times 10^{-4} \mathrm{~Pa}\right)$ respectively. The effective area of each cell was $4 \mathrm{~mm}^{2}$, defined by masks for all the solar cell devices discussed in this work. The current density-voltage $(\mathrm{J}-\mathrm{V})$ curves of the photovoltaic devices were obtained by a Keithley 2400 source-measure unit. The photocurrent was measured under simulated illumination at100 $\mathrm{mW} \mathrm{cm} \mathrm{cm}^{-2} \mathrm{AM} 1.5 \mathrm{G}$ irradiation using a xenon-lamp-based solar simulator (Oriel 96000) in an argon filled glovebox. The simulator irradiance was calibrated using a certified silicon diode.

\subsection{Synthesis}

The synthesis routes of DOR2TDPP and DCAO2TDPP are shown in Scheme 1.

$<<$ Scheme1 $>>$

2.4.1 Synthesis of compound M1. 
LDA (2.0M in hexane, $2.4 \mathrm{ml}, 4.8 \mathrm{mmol})$ was added dropwise to a solution of DPP (1.0 g, $1.9 \mathrm{mmol})$ in anhydrous tetrahydrofuran $(60 \mathrm{ml})$ at $-78{ }^{\circ} \mathrm{C}$ under an argon atmosphere, the mixture was stirred for $2 \mathrm{~h}$, then the mixture was stirred at room temperature for $12 \mathrm{~h}$. Afterwards, tri-n-butyltin chloride $(1.0 \mathrm{M}$ in THF, $4.8 \mathrm{ml}, 4.8 \mathrm{mmol})$ was added to the mixture at $-78{ }^{\circ} \mathrm{C}$ and the reaction mixture was stirred for $2 \mathrm{~h}$, then stirred at room temperature for $24 \mathrm{~h}$. The solution was poured into water and the organic phase was extracted with $\mathrm{CH}_{2} \mathrm{Cl}_{2}$ for three times, and the merged solution was dried with anhydrous sodium sulfate for over $5 \mathrm{~h}$. Solvent was removed by evaporation under vacuum, the product was obtained as dark pink liquid and used in the next step without further purification.

\subsubsection{Synthesis of compound M3.}

A solution of $\mathbf{M} 2(2 \mathrm{~g}, 4.0 \mathrm{mmol})$ andM1 synthesized above in dry toluene (100 mL) was degassed twice with argon followed by the addition of $\mathrm{Pd}\left(\mathrm{PPh}_{3}\right)_{4}(80 \mathrm{mg}, 0.06 \mathrm{mmol})$. After being stirred at $120{ }^{\circ} \mathrm{C}$ for $24 \mathrm{~h}$ under argon, the reaction mixture was poured into water $(100 \mathrm{~mL})$ and extracted with $\mathrm{CHCl}_{3}$. The organic layer was washed with water for three times, and then dried over $\mathrm{Na}_{2} \mathrm{SO}_{4}$. After removal of solvent, the crude product was purified by column chromatography on silica gel usinga mixture of dichloromethane and petroleum ether (1:3) to afford compound M3 $(1.40 \mathrm{~g}, 56 \%)$ as a blue-black solid. ${ }^{1} \mathrm{H} \mathrm{NMR}\left(400 \mathrm{MHz}, \mathrm{CDCl}_{3}\right): \delta 9.868(\mathrm{~s}, 2 \mathrm{H}), 9.028(\mathrm{~d}, 2 \mathrm{H})$, 7.629(s, 2H), 7.367(d, 2H), 7.189(s, 2H), 4.112(m, 4H), 2.893(m, 8H), 1.739(m, 10H), 1.329(m, 67H), 0.905(m, 24H).MS (MALDI-TOF): calculated for $\mathrm{C}_{80} \mathrm{H}_{112} \mathrm{~N}_{2} \mathrm{O}_{4} \mathrm{~S}_{6}[\mathrm{M}]^{+}$, 1358.14; found, 1359.03.

\subsubsection{Synthesis of compound DOR2TDPP}

A solution of M3 $(500 \mathrm{mg}, 0.37 \mathrm{mmol})$ and 3-octyl rhodanine $(900 \mathrm{mg}, 3.7 \mathrm{mmol})$ in dry chloroform was degassed twice with argon followed by the addition of three drops of piperidine. 
After refluxing for $12 \mathrm{~h}$ under argon, the reaction mixture was poured into water $(300 \mathrm{~mL})$ and extracted with $\mathrm{CHCl}_{3}$. The organic layer was washed with water for three times, and then dried over $\mathrm{Na}_{2} \mathrm{SO}_{4}$. After removal of solvent, the crude product was purified by column chromatography on silica gel using a mixture of dichloromethane and petroleum ether (2:1) to afford compound DOR2TDPP(420mg, 63\%) as a black solid. ${ }^{1} \mathrm{H}$ NMR (400 MHz, $\left.\mathrm{CDCl}_{3}\right): \delta 9.09$ (s, 2H), 7.78 (s, 2H), $7.34(\mathrm{~s}, 2 \mathrm{H}), 7.25(\mathrm{~d}, 2 \mathrm{H}), 7.16(\mathrm{~d}, 2 \mathrm{H}), 4.12(\mathrm{~d}, 8 \mathrm{H}), 2.85(\mathrm{t}, 8 \mathrm{H}), 1.98(\mathrm{~m}, 2 \mathrm{H}), 1.75(\mathrm{~m}, 14 \mathrm{H}), 1.44$ (m, 98H), $0.95(\mathrm{~m}, 30 \mathrm{H}) .{ }^{13} \mathrm{C}$ NMR (100 MHz, $\left.\mathrm{CDCl}_{3}\right): 201.180,192.168,167.504,141.831$, $141.497,141.057,139.422,138.967,137.301,136.606,135.525,134.630,134.324,132.311$, 131.547, 130.102, 129.316, 126.824, 124.692, 120.887, 108.459, 44.891, 39.369, 31.880, 31.784, $30.399,30.218,29.749,29.536,29.431,29.370,29.341,29.284,29.145,28.434,26.997,26.805$, 23.607, 23.174, 22.688, 22.641. MS (MALDI-TOF): calculated for $\mathrm{C}_{102} \mathrm{H}_{146} \mathrm{~N}_{4} \mathrm{O}_{4} \mathrm{~S}_{10}[\mathrm{M}]^{+}, 1811.86$; found, 1812.83 .

\subsubsection{Synthesis of compound DCAO2TDPP.}

A solution of $\mathbf{M 3}(500 \mathrm{mg}, 0.37 \mathrm{mmol})$ andoctylcyanoacetate $(0.78 \mathrm{ml}, 3.7 \mathrm{mmol})$ in dry chloroform was degassed twice with argon followed by the addition of three drops of triethylamine. After refluxing for $12 \mathrm{~h}$ under argon, the reaction mixture was poured into water $(300 \mathrm{~mL})$ and extracted with $\mathrm{CHCl}_{3}$. The organic layer was washed with water for three times, and then dried over $\mathrm{Na}_{2} \mathrm{SO}_{4}$. After removal of solvent, the crude product was purified by column chromatography on silica gel using a mixture of dichloromethane and petroleum ether (3:2) to afford compound DCAO2TDPP(450mg, 71\%) as a black solid. ${ }^{1} \mathrm{H}$ NMR (400 MHz, $\left.\mathrm{CDCl}_{3}\right): \delta 9.08(\mathrm{~s}, 2 \mathrm{H}), 8.23(\mathrm{~s}$, 2H), $7.60(\mathrm{~s}, 2 \mathrm{H}), 7.36(\mathrm{~d}, 2 \mathrm{H}), 7.24(\mathrm{~d}, 2 \mathrm{H}), 4.32(\mathrm{t}, 4 \mathrm{H}), 4.09(\mathrm{~d}, 4 \mathrm{H}), 2.87(\mathrm{t}, 8 \mathrm{H}), 1.96(\mathrm{~m}, 2 \mathrm{H})$, $1.76(\mathrm{~m}, 14 \mathrm{H}), 1.33(\mathrm{~m}, 96 \mathrm{H}), 0.90(\mathrm{~m}, 30 \mathrm{H}) .{ }^{13} \mathrm{C} \mathrm{NMR}\left(100 \mathrm{MHz}, \mathrm{CDCl}_{3}\right): 249.690,242.891$, 229.693, 219.804, 211.648, 202.937, 190.936, 182.778, 177.839, 163.068, 140.967, 132.038, 
$130.525,122.391,98.024,66.640,50.142,46.133,42.193,39.334,31.794,30.200,29.738,29.514$, $29.408,29.329,29.271,29.200,28.420,25.822,23.606,23.160,22.688,14.127,10.557$, MS (MALDI-TOF): calculated for $\mathrm{C}_{102} \mathrm{H}_{146} \mathrm{~N}_{4} \mathrm{O}_{6} \mathrm{~S}_{6}[\mathrm{M}]+$, 1715.96; found, 1715.95 .

\section{Results and discussion}

3.1 Thermo-stability.

\section{$<<$ Fig.1 $>>$}

Thermogravimetric analysis (TGA) was used to study the thermo-stability of the two compounds and the TGA curves were shown in Fig. 1. From Fig. 1, we can see that both DOR2TDPP and DCAO2TDPP exhibited good stability with decomposition temperature (Td) more than $350{ }^{\circ} \mathrm{C}$ under $\mathrm{N}_{2}$ atmosphere, indicating good thermo stability for their device application. , DCAO2TDPP showed a little better thermal stability than DOR2TDPP since ring-opening reaction might happen when 3-octyl rhodanine end group is exposed to high temperature.

\subsection{Optical absorption}

The UV-Vis absorption spectra of DOR2TDPP and DCAO2TDPP (in chloroform solution and spin coated film) are shown in Fig. 2. DOR2TDPP and DCAO2TDPP show maximum absorption $631 \mathrm{~nm}$ and $629 \mathrm{~nm}$, respectively, in the chloroform solution. Compared with the absorption in solution, film absorption of the two compounds exhibit a red shift of about $70 \mathrm{~nm}$, and the maximum absorption peaks were $705 \mathrm{~nm}$ for DOR2TDPP and $699 \mathrm{~nm}$ for DCAO2TDPP, which all locate in the near infrared region. In contrast to our previous reported A-D-A molecules $(\mathrm{D}=\mathrm{BDT}$ or oligothiophene), the absorption of DOR2TDPP and DCAO2TDPP showed obvious red shift absorption after introduction of DPP unit as the central core unit. 
3.3 Electrochemical properties and electronic energy level

The cyclic voltammetry (CV) was used to study the electrochemical properties of DOR2TDPP and DCAO2TDPP. The potentials were internally calibrated using the ferrocene/ferrocenium $\left(\mathrm{Fc} / \mathrm{Fc}^{+}\right)$of the redox couple $(4.8 \mathrm{eV}$ below the vacuum level). The energy levels of the HOMO and LUMO are $-5.05 \mathrm{eV}$ and $-3.27 \mathrm{eV}$ for DOR2TDPP, and $-5.12 \mathrm{eV}$ and $-3.33 \mathrm{eV}$ for DCAO2TDPP, which were calculated from the onset oxidation potential and the onset reduction potential. The CV curves were shown in Fig. 3, and the detailed values of HOMO, LUMO and bandgaps of the two compounds were listed in Table 1. Calculated from CV curve, the bandgaps $\left(\mathrm{E}_{\mathrm{g}}{ }^{\mathrm{cv}}\right)$ of DOR2TDPP and DCAO2TDPP are $1.78 \mathrm{ev}$ and $1.79 \mathrm{ev}$, which didn't match with the bandgaps calculated from U-V absorption spectra ( $\mathrm{E}_{\mathrm{g}}^{\mathrm{opt}}$ of DOR2TDPP and DCAO2TDPP are $1.39 \mathrm{ev}$ and $1.40 \mathrm{ev}$, respectively). For our case, we tested the $\mathrm{CV}$ in the corresponding donor dichloromethane solutions. While the optical band gaps were estimated from the sample solid film absorption. That might be the reason of the inconsistence of the bandgap values from $\mathrm{CV}$ and absorption.

\section{$\langle<$ Fig. 3>>}

In order to further investigate the electronic and optical properties of these two DPP based molecules, we performed molecular geometry optimization using density functional theory (DFT) calculation (B3LYP/6-31G*), and frequency analysis was followed that the obtained optimized structures were in stable states. The optimized molecular geometries and frontier molecular orbitals of DOR2TDPP and DCAO2TDPP were shown in Figure S7-9. Time-dependent DFT (TDDFT) calculation of the S0 - S1 transitions were then performed on basis of optimized geometries in the ground states, to investigate the vertical excitation energies by analyzing the lowest 30 singlet roots of the nonhermitian eigenvalue equations. The calculation results were summarized in Table S1-2, and the simulated UV-vis spectra were shown in Figure S10. The calculation results are similar to 
the experimental results and the maximum absorption bands mainly correspond to pure HOMO-LUMO transition with $\pi-\pi^{*}$ character.

3.4 X-Ray diffraction (XRD)

X-Ray diffraction analysis was used to investigate the crystallinity of the two molecules and the patterns were shown in Fig. 4. From Fig. 4, we can see that a strong reflection peak (100) at $2 \theta$ $=4.12^{\circ}$ was observed for DOR2TDPP, corresponding to a $d_{100}$-spacing values of $18.7 \AA$. While the reflection peak (100) of DCAO2TDPP at $2 \theta=4.56^{\circ}$ (corresponding to a $\mathrm{d}_{100^{-}}$-spacing values of 20.7 $\AA$ ) was much weaker comparing with that of DOR2TDPP, indicating that the DOR2TDPP had more ordered packing behavior than DCAO2TDPP.

$<<$ Fig. 4>>

\subsection{Photovoltaic performance}

Solution processed OSCs with a bulk-heterojunction structure were fabricated usingthe two compounds as donor and $\mathrm{PC}_{71} \mathrm{BM}$ as acceptor. The device structure is glass/ITO/PEDOT:PSS/active layer/LiF/Al. The device performance was optimized by adjusting the blend ratio of donor versus acceptor and varying the amount of additive (1, 8-Diiodooctane, DIO). The optimized typical current density-voltage (J-V) curves of devices were shown in Fig. 5 and the results were summarized in Table.2 and Table3.For both of DOR2TDPP and DCAO2TDPP based OSCs, the best performance was obtained from the device with a blend ratio of $1: 1$ together with $3 \%$ DIO, which gave a Voc of $0.76 \mathrm{~V}$, a Jsc of $5.09 \mathrm{~mA} \mathrm{~cm}^{-2}$, a FF of 0.53 and a PCE of $2.05 \%$ for DOR2TDPP, and a Voc of $0.76 \mathrm{~V}$, a Jsc of $3.12 \mathrm{~mA} \mathrm{~cm}^{-2}$, a FF of 0.46 and a PCE of $1.09 \%$ for DCAO2TDPP, respectively. 
Atomic force microscopy (AFM) was applied to study the morphology of the films with different ratio of DIO. As shown in Fig.6, we can see that the two molecules blending films showed much different morphologies when different ratio of DIO were added. For the blending film DOR2TDPP:PCBM, when 3\% DIO was added, the root-mean-squared (RMS) roughness was 7.06 $\mathrm{nm}$, which is lower than that of films with $1 \%(7.76 \mathrm{~nm})$ and $5 \%$ DIO $(12.4 \mathrm{~nm})$. Also, the films with $1 \%$ and $5 \%$ DIO also showed much large phase separation in contrast with the film with $3 \%$ DIO. For the blending film DCAO2TDPP:PCBM, when 1\% DIO was added, a large phase separation was observed with roughness $12.6 \mathrm{~nm}$. The surface became relatively smoother with RMS roughness of $7.05 \mathrm{~nm}$ when 3\% DIO was added. When 5\% DIO was added, the blending film roughness increased to $11.9 \mathrm{~nm}$. There were no obvious interpenetrating structures in the DCAO2TDPP:PCBM blending film and there existed large phase separation when different ratio DIO was added, which is responsible for the poor devices performances of DCAO2TDPP:PCBM devices.

\section{$<<$ Fig. 6>>}

To further investigate the device performance, the external quantum efficiency (EQE) of the two molecules based devices was measured as shown in Fig. 7. From the cures, we can see that the DOR2TDPP and DCAO2TDPP based devices show broad absorption, however, the EQE values are very low (below 30\%), especially, the EQE values are below $10 \%$ from $700 \mathrm{~nm}$ to $900 \mathrm{~nm}$. The low EQE values indicate that the photo-response of the two molecules is not efficient enough to change photons into charge carriers. Though both of the two molecules have broad absorption from ultraviolet to near infrared, the solar light cannot be transformed to electric energy efficiently, especially the near infrared light. The energy of the excitons excited by the near infrared light may be relatively lower than that of excitons visible light excited, and could not separate effectively, then 
bimolecular combination occurred and finally resulted in low Jsc.

$$
<<\text { Fig.7 >> }
$$

\section{Conclusion}

In conclusion, two new small molecules with a DPP core were designed and synthesized for solution-processed small molecule organic solar cells. As expected, both of the two molecules have a broad and red shifted absorption compared with that of the molecules our group synthesized before. However, the devices performances were poor owing to the large domain size and phase separation. Although the morphologies could be tuned through various strategies such as additive, thermal annealing and etc., the intrinsic properties, especially the intrinsic packing behaviors are needed to further be investigated, which play a great role on the morphology forming. Thus, it is still a challenge to design molecules which could meet all the demands of high photovoltaic devices.

\section{Acknowledgement}

The authors gratefully acknowledge financial support from the MOST (Grants2014CB643502), NSFC(Grants 91433101, 51422304, and 51373078),NSF of Tianjin City (Grant 13RCGFGX01121), and PCSIRT (IRT1257).

\section{References}

[1]Zhang Q, Kan B, Liu F, Long GK, Wan XJ, Chen XQ, Zuo Y, Ni W, Zhang HJ, Li MM, Hu ZC, Huang F, Cao Y, Liang ZQ, Zhang MT, Russell TP, Chen YS. Small-molecule solar cells with efficiency over 9\%. Nat Photon 2015; 9: 35-41.

[2] Kan B, Zhang Q, Li MM, Wan XJ, Ni W, Long GK, Wang YC, Yang X, Feng HR, Chen YS. Solution-processed organic solar cells based on dialkythio substituted benzodithiophene unit with efficiency near 10\%. J Am Chem Soc 2014; 136: 15529-15532. 
[3] Kan B, Li MM, Zhang Q, Liu F, Wan XJ, Wang YC, Ni W, Long GK, Yang X, Feng HR, Zuo Y, Zhang MT, Huang F, Cao Y, Russell TP, Chen YS. A series of simple oligomer-like small molecules based on oligothiophenes for solution-processed solar cells with high efficiency. J Am ChemSoc2015; 137:3886-3893.

[4] Liu YH, Zhao JB, Li ZK, Mu C, Hu HW, Jiang K, Lin HR, Ade H, Yan H. Aggregation and morphology control enables multiple cases of high-efficiency polymer solar cells. NatComm 2014; 5: 5293.

[5] Kong J, Hwang IW, Lee K. Top-Down approach for nanophase reconstruction in bulk heterojunction Solar Cells. Adv Mater 2014; 26: 6275-6283.

[6] Chen JD, Cui CH, Li YQ, Zhou L, Ou QD, Li C, Li YF, Tang JX. Single-Junctionpolymer solar cells exceeding 10\% power conversion efficiency. Adv Mater 2015; 27: 1035-1041.

[7] Liu C, Yi C, Wang K, Yang YL, Bhatta RS, Tsige M, Xiao SY, Gong X. Single-Junction polymer solar cells with over $10 \%$ efficiency by a novel two-dimensional donor-acceptor conjugated copolymer. ACS Appl Matter Interface 2015; 7: 4928-4935.

[8] He ZC, Xiao B, Liu F, Wu HB, Yang YL, Xiao S, Wang C, Russell TP, Cao Y. Single-junction polymer solar cells with high efficiency and photovoltage. Nat Photon 2015; 9: 174-179.

[9] Kim J, Hong ZR, Li G, Song TB, Chey J, Lee YS, You JB, Chen CC, Sadana DK, Yang Y. 10.5 \% efficient polymer and amorphous silicon tandem photovoltaic cell. Nat Comm 2015; 6:6391.

[10] Ouyang XH, Peng RX, Ai L, Zhang XY, Ge ZY. Efficient polymer solar cells employing a non-conjugated small-molecule electrolyte. Nat Photon 2015; 9: 520-524.

[11] Zhang JQ, Zhang YJ, Fang J, Lu K, Wang ZY, Ma W, Wei ZX. Conjugated polymer-small molecule alloy leads to high efficient ternary organic solar cells. J Am Chem Soc 2015; 137: 8176-8183. 
[12] Lee JK,Ma WL, Brabec CJ,Yuen J, Moon JS, Kim JY, Lee K, Bazan GC, HeegerAJ. Processing additives for improved efficiency from bulk heterojunction solar cell. J Am Chem Soc 2008; 130:3619-3623.

[13] Yao Y, Hou JH, Xu Z, Li G, Yang Y. Effect of solvent mixtures on the nanoscale phase separation in polymer solar cells. Adv Funct Matter 2008; 18: 1783-1789.

[14] Hoven CV, Dang XD, Coffin RC, Peet J,Nguyen TQ, Bazan GC. Improved performance of polymer bulk heterojuction solar cells through the reduction of phase separation via solvent additives. Adv Mater 2010; 22: E63-E66.

[15] Zhao GJ, Zhao YJ, Li YF. $6.5 \%$ efficiency of polymer solar cells based on poly(3-hexylthiophene) and indene- $\mathrm{C}_{60}$ bisadduct by device optimization. Adv Mater 2010;22: $4355-4358$.

[16] Li G, Yao Y, Yang HC, Shrotriya V, Yang G, Yang Y.“Solvent annealing” effect in polymer solar cells based on poly(3-hexylthiophene) and methanofullerenes. Adv Funct Mater 2007; $17: 1636-1644$.

[17] Miller S,Fanchini G,Lin YY,Li C,Chen CW,Su WF, Chhowalla M. Investigation of nanoscale morphological changes in organic photovoltaics during solvent vapor annealing. J Mater Chem 2008; 18: 306-312.

[18] Wang K,Yi C,Hu XW,Liu C,Sun Y,Hou JH,Li YF,Zheng J, Chuang S,Karim A,Gong X. Enhanced performance of polymer solar cells using PEDOT:PSS doped with $\mathrm{Fe}_{3} \mathrm{O}_{4}$ magnetic nanoparticles aligned by an external magnetostatic field as an anode buffer layer. ACS Appl Mater Interfaces 2014; 6: 13201-13208.

[19] Ha DH, Fang ZQ, Hu LB, Munday JN. Paper-based anti-reflection coatings for photovoltaics. Adv Energy Mater 2014;4: 1301804. 
[20] Chen JD, Zhou L, Ou QD, Li YQ, Shen S, Lee ST, Tang JX. Enhanced light harvesting in organic solar cells featuring a biomimetic active layer and a self-cleaning antireflective coating. Adv Energy Mater 2014; 4: 1301777.

[21] Walker B,Tomayo AB,Dang XD,Zalar P,Seo JH,Garcia A,Tantiwiwat M, Nguyen TQ.Nanoscale phase separation and high photovoltaic efficiency in solution-processed, small-molecule bulk heterojunction solar cells. Adv Funct Mater 2009; 19: 3063-3069.

[22] Qu SY, Tian H. Diketopyrrolopyrrole (DPP)-based materials for organic photovoltaics. Chem Commun 2012; 48: 3039-3051.

[23] Chen YS, Wan XJ, Long GK. High performance photovoltaic applications using solution processed small molecules. Acc Chem Res 2014; 46: 2645-2655.

[24] Ni W, Li MM, Wan XJ, Zuo Y, Kan B, Feng HR, Zhang Q, Chen YS. A new oligobenzodithiophene end-capped with 3-ethyl-rhodanine groups for organic solar cells with high open-circuit voltage. Sci Chin Chem 2015; 58: 339-346.

[25] Li MM, Ni W, Feng HR, Kan B, Wan XJ, Zhang YM, Yang X, Chen YS. Dithienopyrrole Based Small Molecule with Low Band Gap for Organic Solar Cells. Chin J Chem 2015; 33: $852-858$

[26] Liu YS, Wan XJ, Wang F, Zhou JY, Long GK, Tian JG, Chen YS. High-performance solar cells using a solution-processed small molecule containing benzodithiophene Unit. Adv Mater 2011;23: 5387-5391. 


\section{Figure captions}

Scheme1. Synthesis routes of DOR2TDPP and DCAO2TDPP.

Fig.1 TGA curves of DOR2TDPP and DCAO2TDPP

Fig. 2 Absorption spectra of DOR2TDPP and DCAO2TDPP in chloroform solution and films.

Fig. 3 Cyclic voltammograms of DCAO2TDPP and DOR2TDPP in a dichloromethane solution of $0.1 \mathrm{~mol} \mathrm{~L}^{-1}$ Bu4NPF6 with a scan rate of $100 \mathrm{mV} \mathrm{S}^{-1}$ on a Pd/C electrode.

Fig. 4 XRD patterns of DCAO2TDPP and DOR2TDPP films spin-coated from $\mathrm{CHCl}_{3}$ onto glass substrate.

Fig. 5 Current density-Voltage characteristics of the OSC devices based on DOR2TDPP and DCAO2TDPP.

Fig. 6 AFM images of Donor : $\mathrm{PC}_{71} \mathrm{BM}$ films spin-coated from their chloroform solution at a weight ratio of 1:1, (a)DOR2TDPP : PC ${ }_{71}$ BMwith1\% DIO, (b) DOR2TDPP : PC $_{71} \mathrm{BM}$ with $3 \%$ DIO, (c) DOR2TDPP : $\mathrm{PC}_{71} \mathrm{BM}$ with $5 \% \mathrm{DIO}$, (d) DCAO2TDPP : $\mathrm{PC}_{71} \mathrm{BM}$ with $1 \% \mathrm{DIO}$, (e) DCAO2TDPP : $\mathrm{PC}_{71} \mathrm{BM}$ with $3 \%$ DIO, (f) DCAO2TDPP : $\mathrm{PC}_{71} \mathrm{BM}$ with $5 \%$ DIO

Fig.7 EQE curves for both devices based on DOR2TDPP and DCAO2TDPP.<smiles>CCN1C(=O)C2=C(c3cccs3)N(P)C(=O)C2=C1c1cccs1</smiles>

DPP

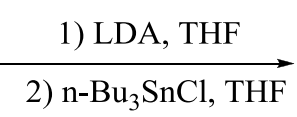

2) $\mathrm{n}-\mathrm{Bu}_{3} \mathrm{SnCl}, \mathrm{THF}$

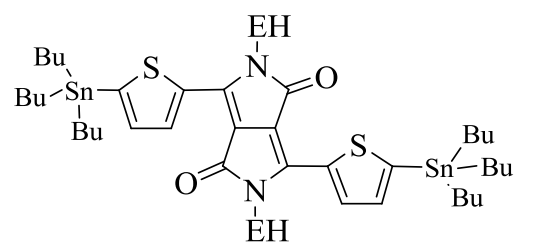

M1

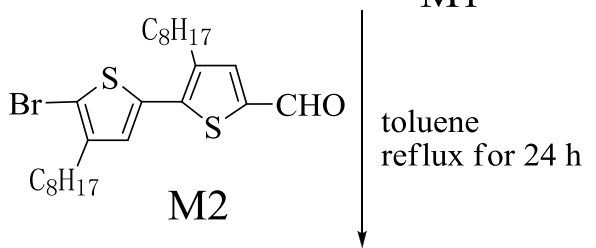

DCAO2TDPP<smiles>C1CC[C@H]2CCCC2C1</smiles>

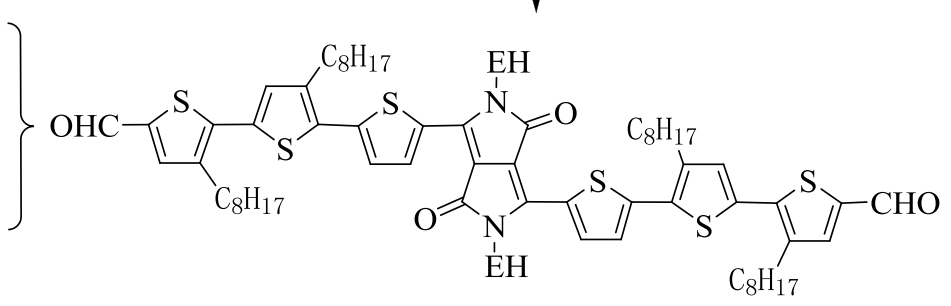

M3

Scheme1. Synthesis routes of DOR2TDPP and DCAO2TDPP. 


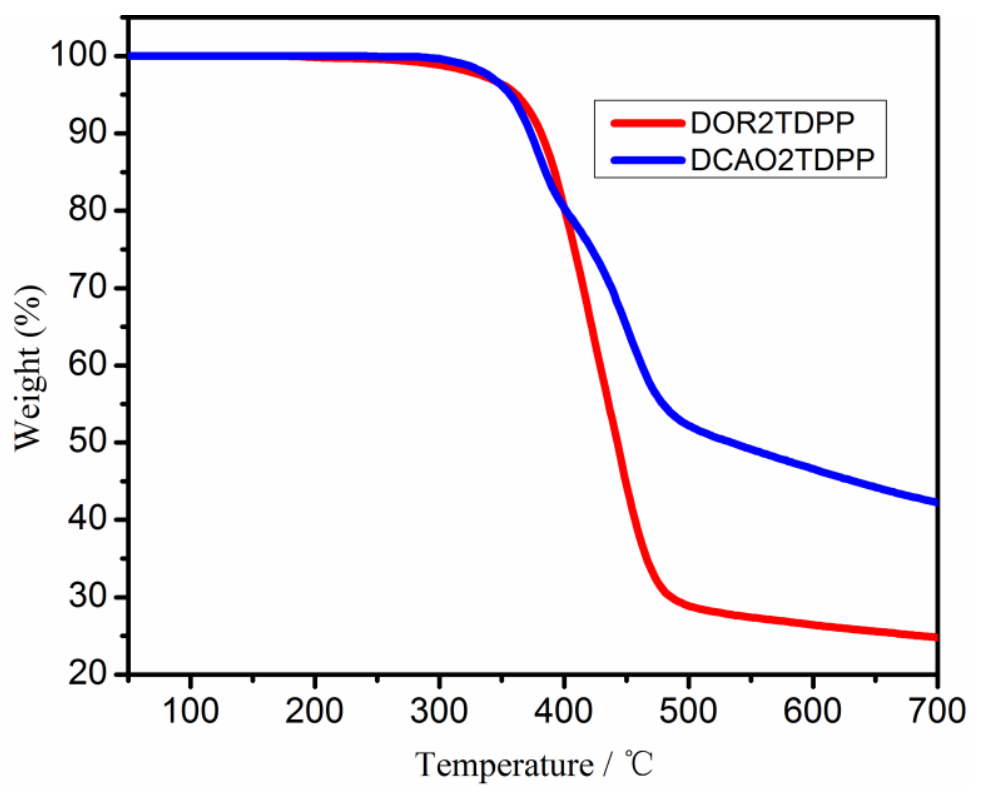

Fig.1 TGA curves of DOR2TDPP and DCAO2TDPP 


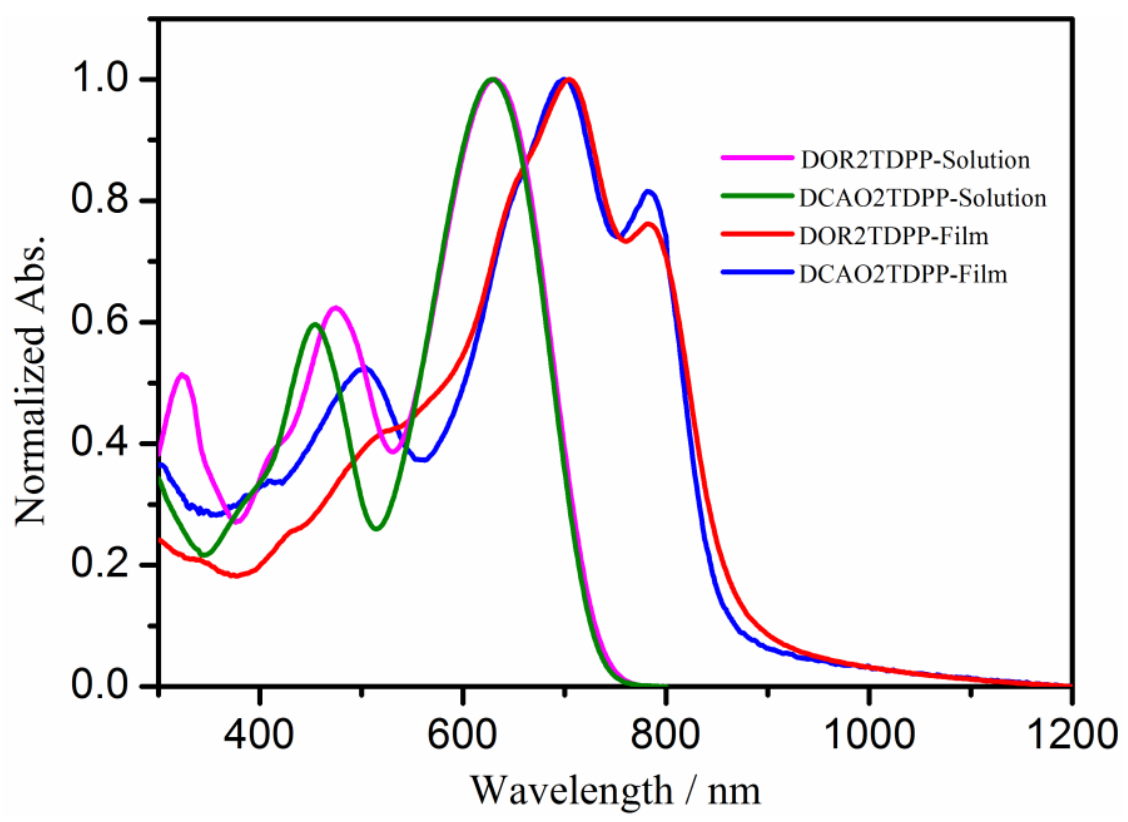

Fig. 2 Absorption spectra of DOR2TDPP and DCAO2TDPP in chloroform solution and films. 


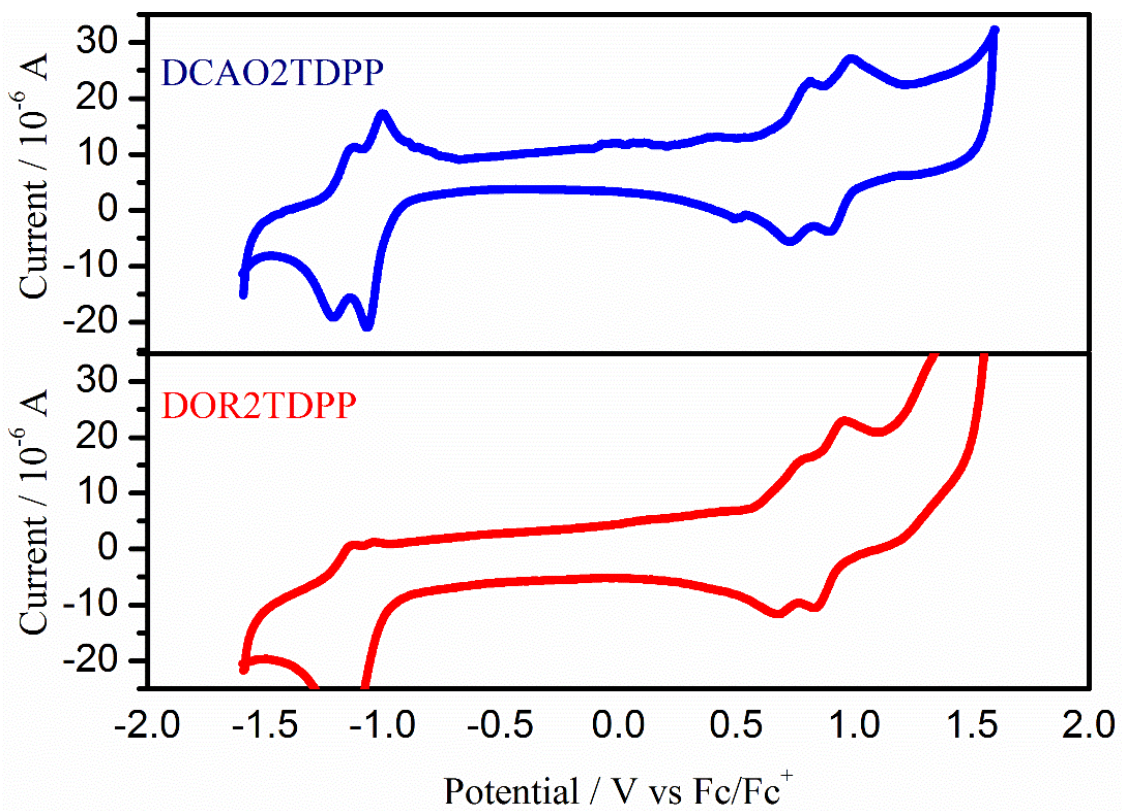

Fig. 3 Cyclic voltammograms of DCAO2TDPP and DOR2TDPP in a dichloromethane solution of $0.1 \mathrm{~mol} \mathrm{~L}^{-1}$ Bu4NPF6 with a scan rate of $100 \mathrm{mV} \mathrm{S}^{-1}$ on a Pd/C electrode. 


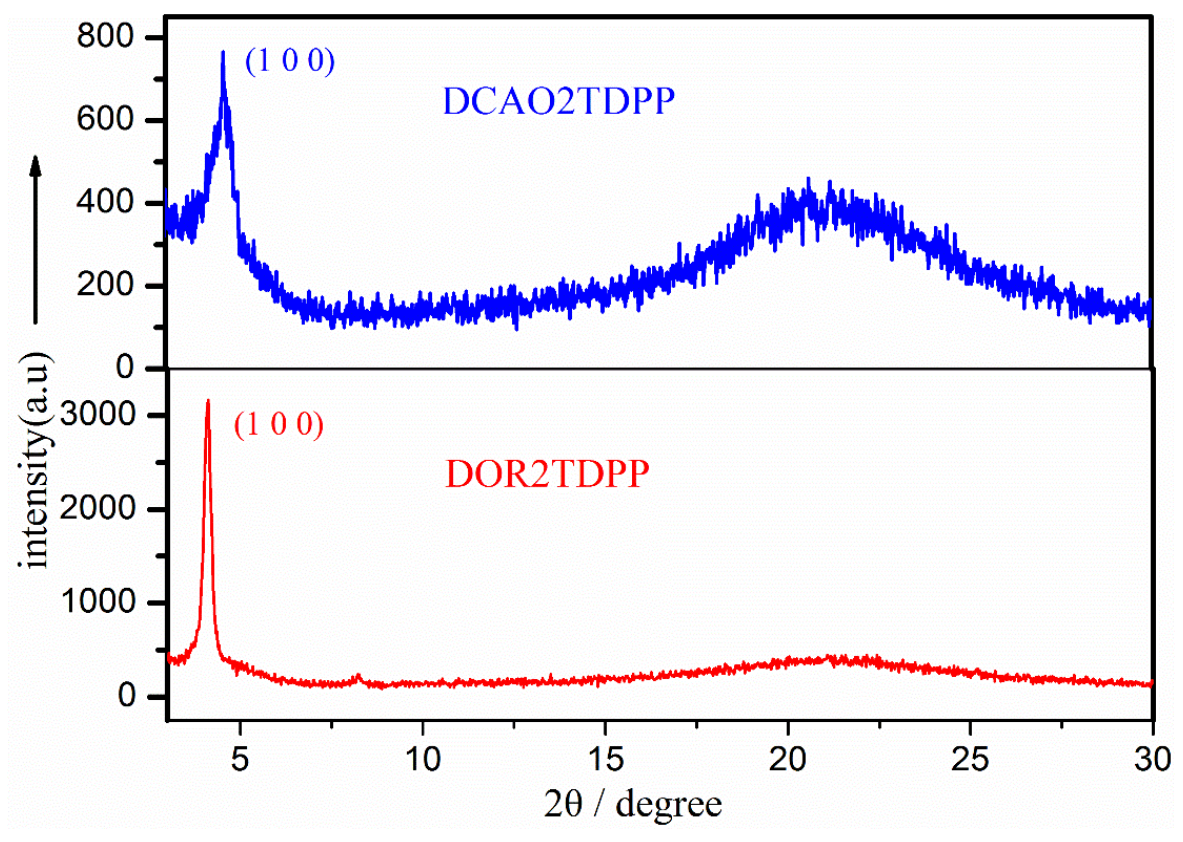

Fig. 4 XRD patterns of DCAO2TDPP and DOR2TDPP films spin-coated from $\mathrm{CHCl}_{3}$ onto glass substrate. 


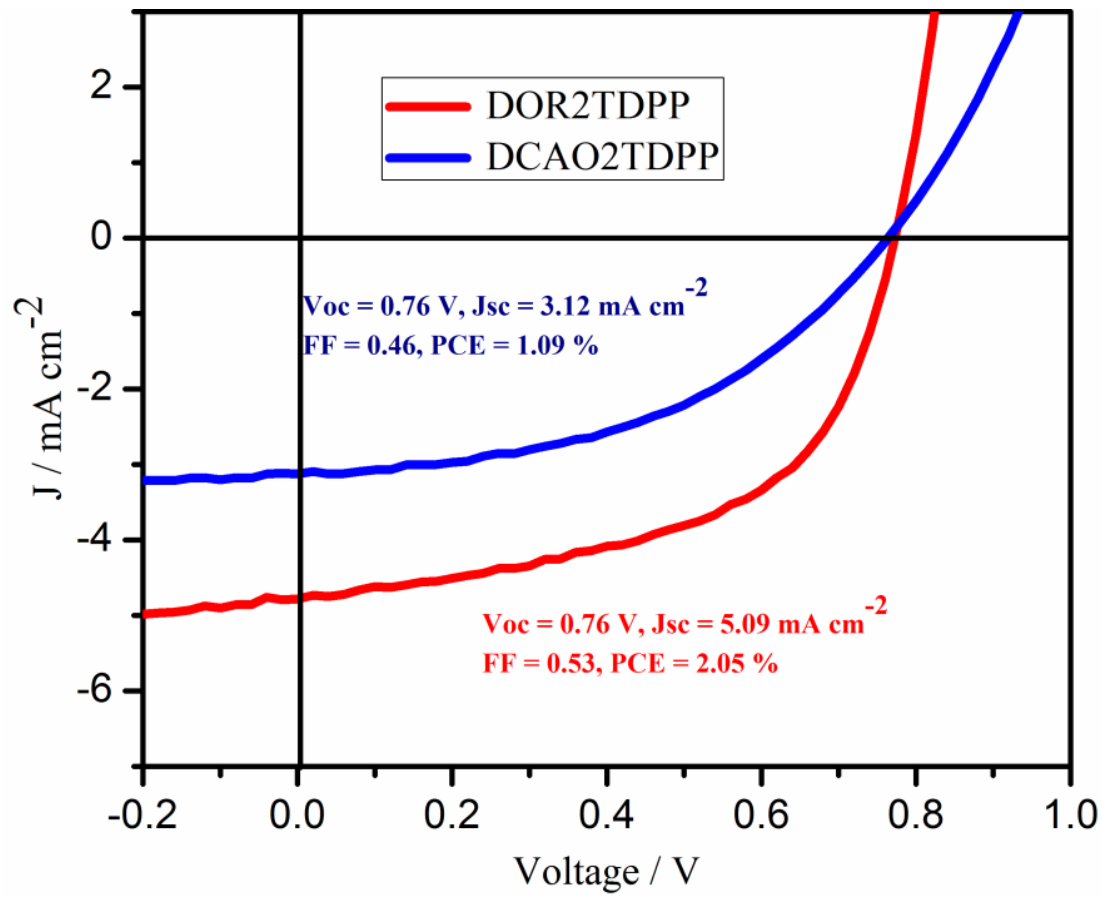

Fig. 5 Current density-Voltage characteristics of the OSC devices based on DOR2TDPP and DCAO2TDPP. 

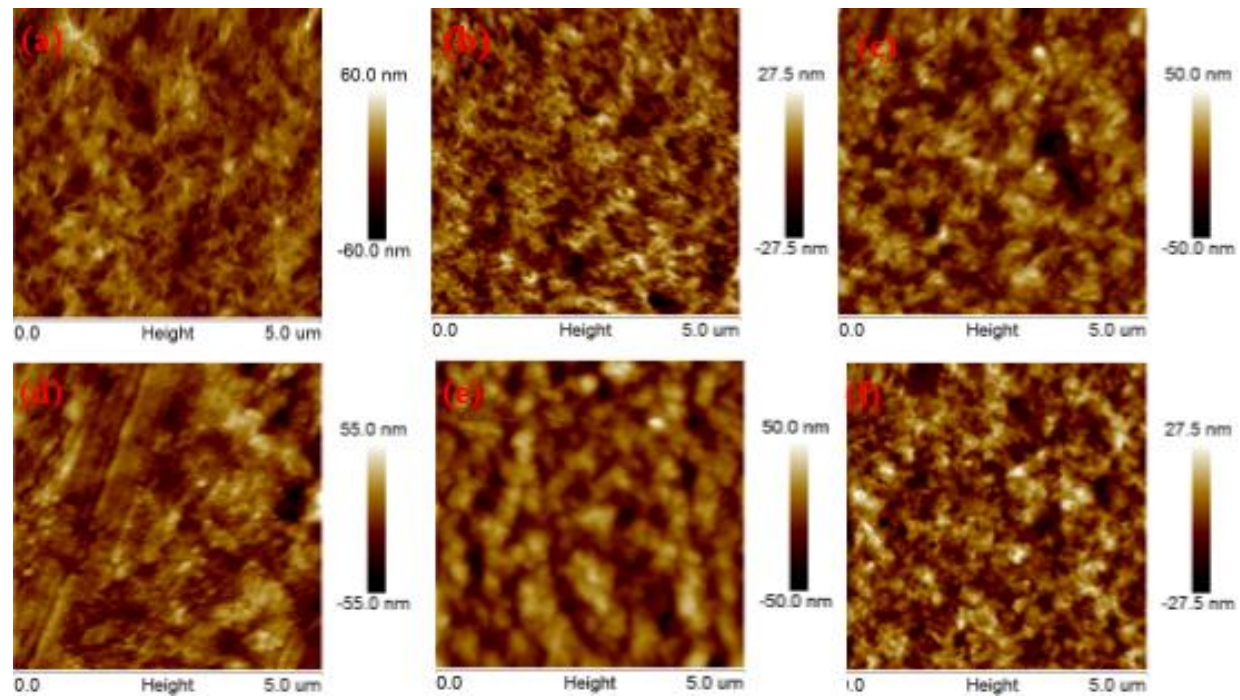

Fig. 6 AFM images of Donor : $\mathrm{PC}_{71} \mathrm{BM}$ films spin-coated from their chloroform solution at a weight ratio of 1:1,

(a)DOR2TDPP : PC ${ }_{71}$ BMwith1\% DIO, (b) DOR2TDPP : PC ${ }_{71} \mathrm{BM}$ with $3 \%$ DIO, (c) DOR2TDPP :

$\mathrm{PC}_{71} \mathrm{BM}$ with 5\% DIO, (d) DCAO2TDPP : $\mathrm{PC}_{71} \mathrm{BM}$ with $1 \%$ DIO, (e) DCAO2TDPP : $\mathrm{PC}_{71} \mathrm{BM}$ with 3\% DIO,

(f) DCAO2TDPP : $\mathrm{PC}_{71} \mathrm{BM}$ with $5 \%$ DIO 


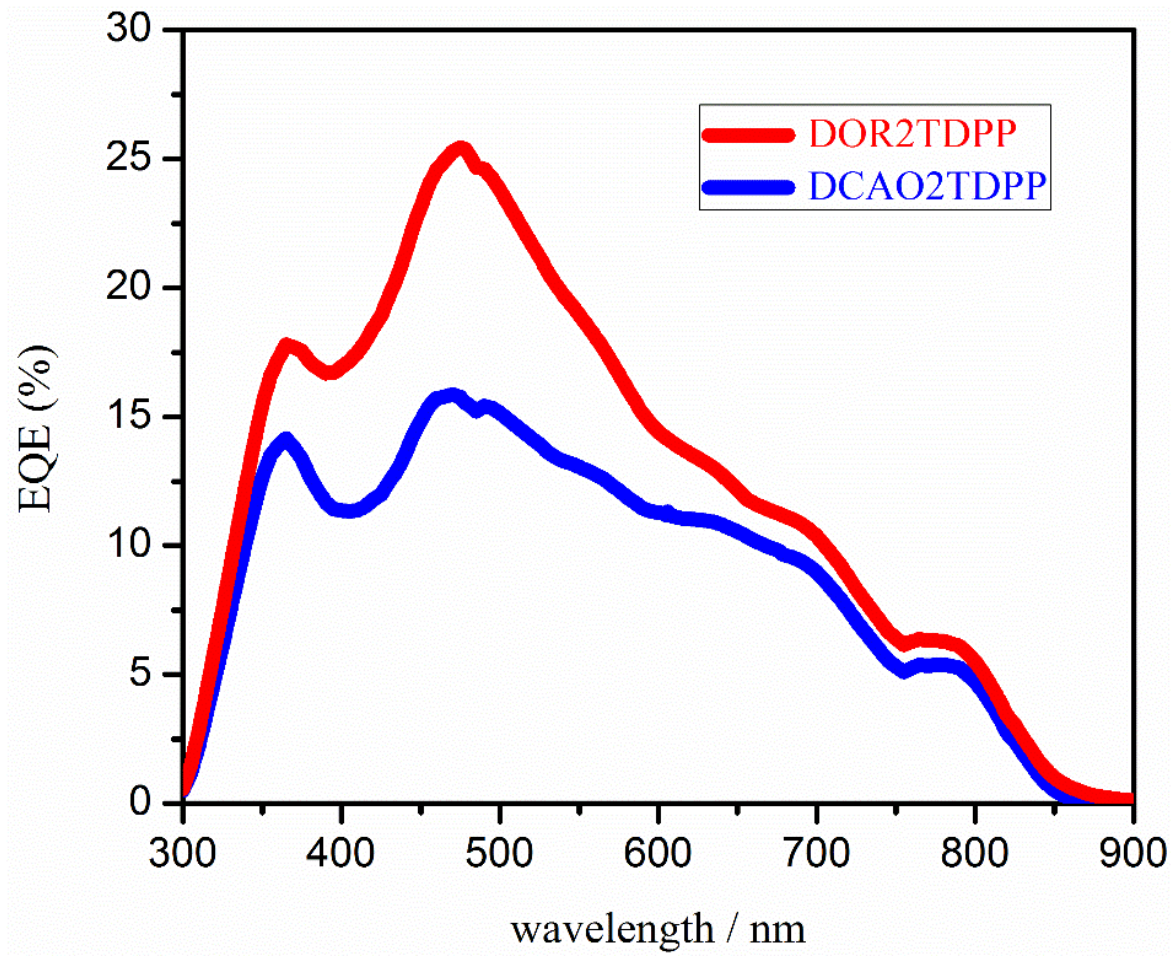

Fig.7 EQE curves for both devices based on DOR2TDPP and DCAO2TDPP. 
Table.1 Optical and electrochemical data of compound DOR2TDPPand DCAO2TDPP

\begin{tabular}{ccccccc}
\hline Compounds & $\begin{array}{c}\lambda_{\max } \\
\text { solution } / \mathrm{nm}\end{array}$ & $\begin{array}{c}\lambda_{\max } \\
\text { film/nm }\end{array}$ & $E_{\mathrm{g}}{ }^{\mathrm{opt}} / \mathrm{eV}$ & $E_{\mathrm{g}}{ }^{\mathrm{CV}} / \mathrm{eV}$ & $\mathrm{HOMO} / \mathrm{eV}$ & $\mathrm{LUMO} / \mathrm{eV}$ \\
\hline DOR2TDPP & 631 & $705 \& 785$ & 1.39 & 1.78 & -5.05 & -3.27 \\
DCAO2TDPP & 629 & $699 \& 782$ & 1.40 & 1.79 & -5.12 & -3.33 \\
\hline
\end{tabular}

Table.2 Influence of D/A ratio on the performance of the SM-OPVs based on DCAO2TDPP and DOR2TDPP.

\begin{tabular}{|c|c|c|c|c|c|}
\hline Compound & Blend ratio (D:A) & $\mathrm{Voc} / \mathrm{V}$ & $\mathrm{Jsc} / \mathrm{mA} \mathrm{cm}^{-2}$ & $\mathrm{FF}$ & $\operatorname{PCE}(\%)$ \\
\hline \multirow[t]{4}{*}{ DCAO2TDPP } & $1: 0.5$ & 0.76 & 1.60 & 0.32 & 0.38 \\
\hline & $1: 0.8$ & 0.77 & 1.49 & 0.26 & 0.29 \\
\hline & $1: 1$ & 0.77 & 2.44 & 0.41 & 0.77 \\
\hline & $1: 1.2$ & 0.77 & 2.10 & 0.40 & 0.64 \\
\hline \multirow[t]{4}{*}{ DOR2TDPP } & $1: 0.5$ & 0.75 & 3.91 & 0.48 & 1.40 \\
\hline & $1: 0.8$ & 0.74 & 4.32 & 0.47 & 1.50 \\
\hline & $1: 1$ & 0.74 & 5.11 & 0.45 & 1.70 \\
\hline & $1: 1.2$ & 0.77 & 4.01 & 0.53 & 1.63 \\
\hline
\end{tabular}


Table.3 Influence of amount of DIO on the performance of the SM-OPVs based on DCAO2TDPP and DOR2TDPP with $\mathrm{D} / \mathrm{A}=1: 1$.

\begin{tabular}{lccccc}
\hline Compound & DIO $(\%)$ & Voc/ V & Jsc $/ \mathrm{mA} \mathrm{cm}^{-2}$ & FF & PCE \\
& & & & & $(\%)$ \\
\hline DCAO2TDPP & 1 & 0.77 & 2.55 & 0.39 & 0.76 \\
& 3 & 0.76 & 3.12 & 0.46 & 1.09 \\
DOR2TDPP & 5 & 0.75 & 1.79 & 0.40 & 0.53 \\
& 1 & 0.75 & 4.82 & 0.53 & 1.91 \\
& 3 & 0.76 & 5.09 & 0.53 & 2.05 \\
& 5 & 0.76 & 4.39 & 0.52 & 1.73 \\
\hline
\end{tabular}




\section{Graphical abstract}

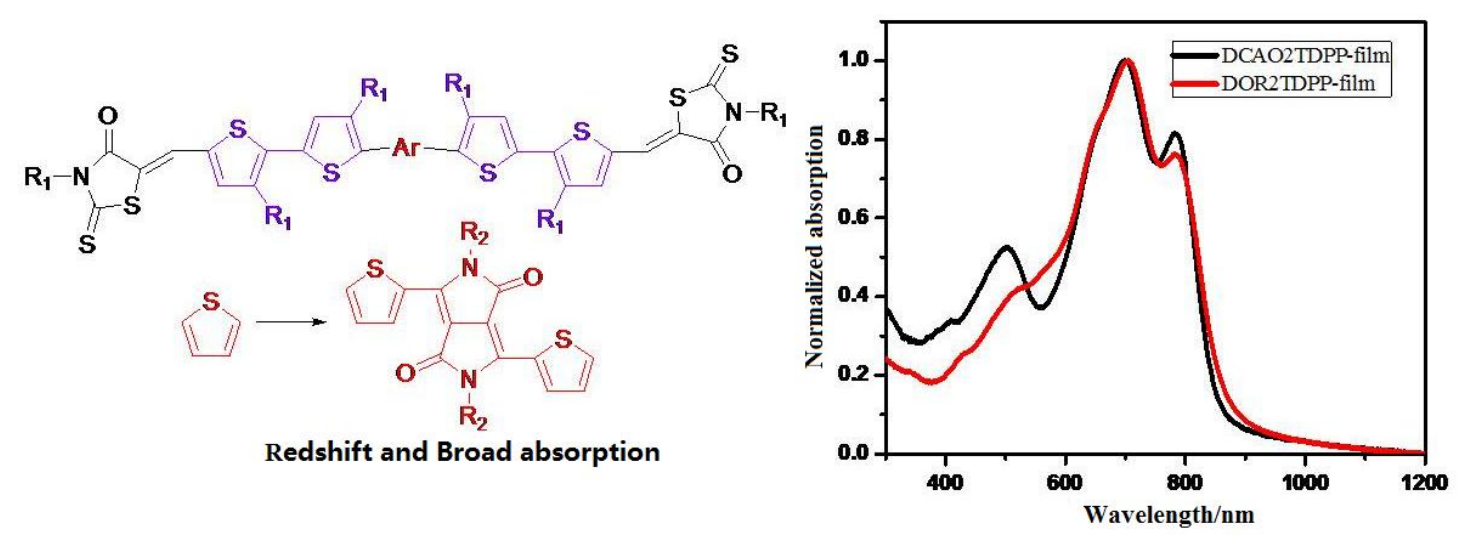

